\title{
STUDI POPULASI BURUNG FAMILI ARDEIDAE DI RAWA PACING DESA KIBANG PACING KECAMATAN MENGGALA TIMUR KABUPATEN TULANG BAWANG PROVINSI LAMPUNG
}

\section{(POPULATION STUDIES OF ARDEIDAE FAMILY BIRD IN RAWA PACING AT KIBANG PACING VILLAGE, MENGGALA TIMUR SUB-DISTRICT, LAMPUNG PROVINCE)}

\author{
Julyanto $^{1)}$, Sugeng P. Harianto ${ }^{1)}$, dan Nuning Nurcahyani ${ }^{2)}$ \\ ${ }^{1)}$ Mahasiswa Jurusan Kehutanan, Fakultas Pertanian, Universitas Lampung \\ ${ }^{2)}$ Dosen Jurusan Biologi, Fakultas MIPA, Universitas Lampung \\ J1. Soemantri Brojonegoro No. 1 Bandar Lampung, 35145 \\ E-mail : julyantoforester@gmail.com \\ Phone : +6282280529197
}

\begin{abstract}
ABSTRAK
Desa Kibang Pacing dengan luas wilayah $83,55 \mathrm{~km}^{2}$ terletak di sebelah Timur Kecamatan Menggala Timur. Daerah ini merupakan rawa pasang surut yang sebagian besar wilayahnya dimanfaatkan sebagai kawasan budidaya dengan didominasi oleh tanaman sawit. Alih fungsi lahan ini menyebabkan adanya perubahan pada tutupan vegetasi yang semula multi menjadi mono strata. Alih fungsi lahan ini menyebabkan terganggunya komponen habitat alami serta populasi berbagai jenis satwa khususnya burung air Ardeidae. Untuk mengetahui populasi burung Ardeidae dilakukan penelitian dengan metode tiga titik hitung (Point Count). Pengamatan dilakukan selama 18 hari efektif dengan diam pada titik hitung dan mencatat burung yang dijumpai. Hasil penelitian dianalisis dan dihitung menggunakan rumus kelimpahan populasi dan pola penyebaran setiap spesies Ardeidae. Berdasarkan hasil penelitian diketahui bahwa populasi blekok sawah 64 ekor, bambangan merah 4 ekor, cangak merah 11 ekor, kuntul besar 89 ekor, kuntul kecil 333 ekor, kuntul kerbau 112 ekor. kelimpahan total rerata pada semua spesies famili Ardeidae adalah 613 ekor. kelimpahan populasi Ardeidae terendah sebanyak 4 ekor dan tertinggi sebanyak 333 ekor. Pola penyebaran populasi Ardeidae di Desa Kibang Pacing adalah mengelompok.
\end{abstract}

Kata kunci: Ardeidae, burung, Kibang Pacing, populasi

\section{ABSTRACT}

Kibang pacing village with 83,55 $\mathrm{Km}^{2}$ areas, is located at the East of Menggala Timur sub district. This area is valley which most of the area has been used for coconut oil cultivation. The changed of this area made the vegetation cover this area changed from a multi stration area to the mono stration. This changed over the area caused the hampered of nature habitat component and the population of kinds of animals, especially Ardeidae water bird. To know the Ardeidae population in this research with use point count three method. This research done for 18 days effectively with stayed at the point and noted the birds founded. The result of research done analyze and can be used to count this population and distribution pattern of Ardeidae species. Based on the research showed the population is 64 birds blekok rice, 4 Cinnamon Bittern bird, 11 red cangak birds, 89 great egret birds, 333 little egret birds, 112 buffalo birds. The mean of all Ardeidae family was 613 birds. The lowest population of Ardeidae was 4 birds and the highest was 333 birds. The distribution patern of Ardeidae population at Kibang Pacing village is group pattern.

Keywords : Ardeidae, birds, Kibang Pacing, population 


\section{PENDAHULUAN}

\section{A. Latar Belakang}

Desa Kibang Pacing dengan luas wilayah $83,55 \mathrm{~km}^{2}$ terletak di sebelah Timur Kecamatan Menggala Timur merupakan daerah rawa pasang surut (Badan Pusat Statistik, 2014) yang sebagian besar luasan wilayahnya dimanfaatkan sebagai kawasan budidaya dengan didominasi oleh tanaman sawit. Pemerintah Kabupaten Tulang Bawang memasukkan tanaman sawit sebagai tanaman komoditi potensi daerah.

Ardeidae merupakan jenis burung air tipe perancah, yaitu berkaki dan berparuh panjang yang berguna untuk hidup di dekat atau di dalam lahan basah (Howes, 2003). Ardeidae memiliki persebaran hampir merata di seluruh wilayah Indonesia seperti Sumatera, Jawa, Kalimantan dan Bali (McKinnon, 1998). Kehadiran burung merupakan suatu indikator penting dalam kehidupan sehingga perlu dilakukan kegiatan konservasi sebagai upaya perlindungan dan pelestarian burung untuk mempertahankan keberadaan burung di alam. Keberadaan spesies-spesies dari Ardeidae juga dapat menjadi indikator ekosistem lingkungan maupun tanaman air yang masih terjaga (Chrystanto, 2014).

Dari dua puluh empat spesies famili Ardeidae yang terdapat di Indonesia setengahnya merupakan burung yang dilindungi menurut Undang- Undang No.5 tahun 1990 tentang Konservasi Sumber Daya Alam Hayati dan Ekosistemnya dan Peraturan Pemerintah No.7 tahun 1999 tentang Pengawetan Jenis Tumbuhan dan Satwa (Noerdjito, 2001).

Upaya perlindungan dan pelestarian burung tidak hanya dapat dilakukan pada kawasankawasan konservasi yang telah ditetapkan pemerintah saja, namun kegiatan konservasi burung juga dapat dilakukan di kawasan budidaya seperti kawasan perkebunan dan kawasan pertanian. Oleh karena itu perlu dilakukan penelitian mengenai populasi burung sebagai acuan dalam upaya pelestarian burung pada kawasan budidaya di Desa Kibang Pacing Kecamatan Menggala Timur.

\section{B. Tujuan Penelitian}

Tujuan dilakukan penelitian ini yaitu untuk mengetahui:

1. Populasi burung famili Ardeidae pada Rawa Pacing di Desa Kibang Pacing

2. Populasi dari setiap spesies famili Ardeidae

\section{METODE PENELITIAN}

\section{A. Waktu dan Tempat Penelitian}

Penelitian ini dilakukan pada bulan Agustus-September 2015 di Desa Kibang Pacing Kecamatan Menggala Timur Kabupaten Tulang Bawang. Penelitian dilakukan dengan menggunakan metode titik hitung (Point Count) atau IPA (Indices Ponctuele d'Abundance Indeks Kelimpahan pada Titik). Pengamatan menggunakan tiga titik hitung di lokasi pengamatan dengan jarak antar titik pengamatan \pm 300 meter. Waktu pengamatan selama 180 menit dibagi tiga, waktu pengamatan di masing-masing titik pengamatan \pm 50 menit sedangkan \pm 15 menit adalah waktu untuk berjalan ke titik pengamatan selanjutnya. Pengamatan dilakukan pada pagi hari pukul 06.00-09.00 WIB dan pada sore hari pukul 15.00-18.00 WIB. Pengamatan dilakukan secara berulang sebanyak 3 kali pengulangan untuk setiap lokasi pengamatan. Perhitungan populasi dilakukan dengan menghitung langsung jumlah burung yang diamati serta berdasarkan informasi dari masyarakat sekitar Desa Kibang Pacing untuk mendukung data yang diperoleh di lapangan.

Pelaksanaan dilakukan dengan diam pada titik yang telah ditentukan, kemudian perjumpaan dengan burung dicatat. Parameter yang diukur yaitu jenis burung, jumlah burung, 
dan waktu perjumpaan. Pengamatan menggunakan tiga titik hitung/stasiun pengamatan (Gambar 1).

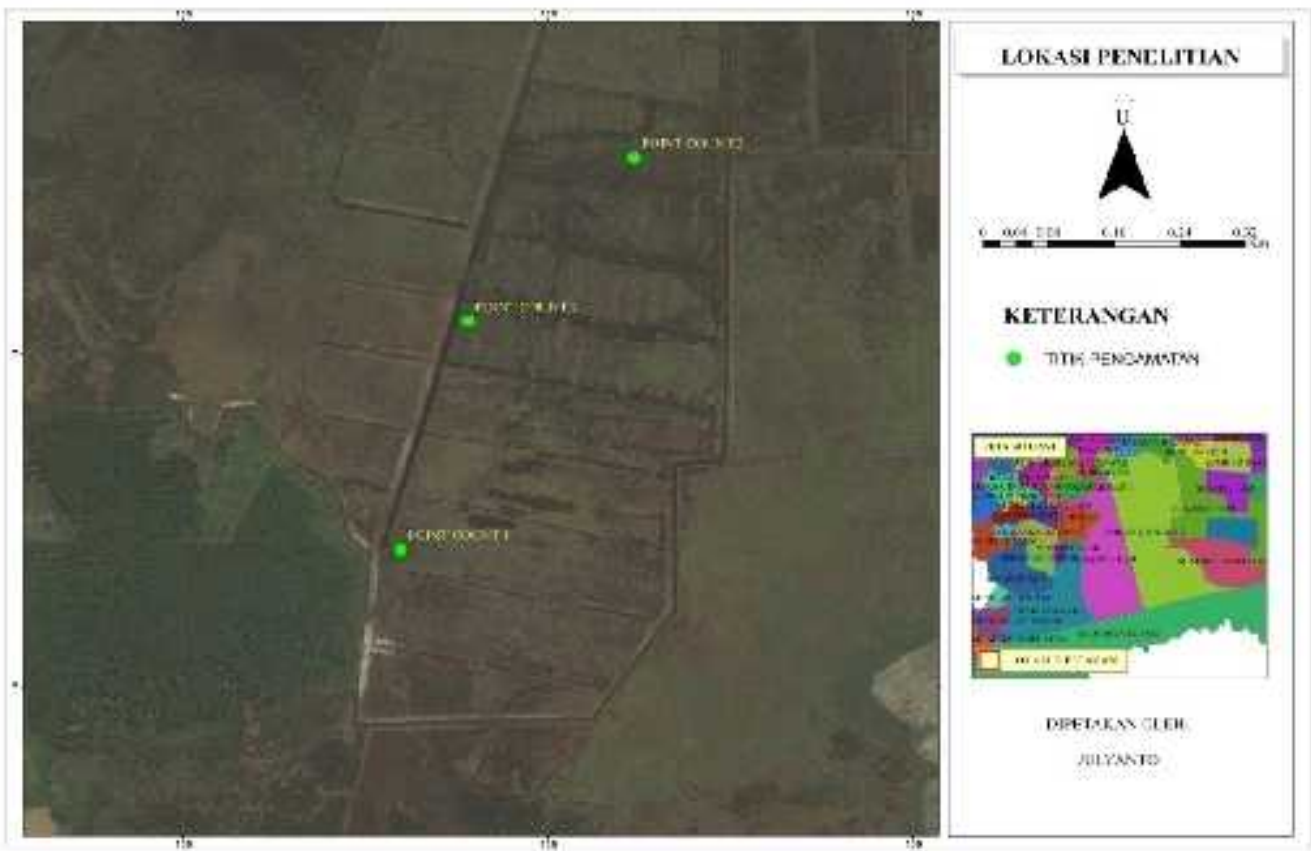

Gambar 1. Peta lokasi penelitian Desa Kibang Pacing Kecamatan Menggala Timur Kabupaten Tulang Bawang (Julyanto, 2015).

Kondisi umum areal pengamatan diamati dengan metode rapid assessment yang merupakan modifikasi dari habitat assessment untuk mendapatkan gambaran secara umum tipe vegetasi di tempat keberadaan burung.

Menurut Kwatrina, Kuswanda dan Setyawati (2013), ukuran kelompok merupakan jumlah individu dalam kelompok. Data ukuran kelompok dikumpulkan dengan mencatat jumlah individu dan lokasi sesuai keberadaan kelompok yang ditemukan. Dugaan kelimpahan populasi Ardeidae diperoleh dari perhitungan dengan rumus (Yuniar, 2007):

$\mathrm{P}=\bar{X} \pm \mathrm{t} . \mathrm{SE}$

Dimana :

$\mathrm{P} \quad=$ Populasi

$\bar{X} \quad=$ Rata-rata

$\mathrm{X} \quad=$ Jumlah individu

$\mathrm{n} \quad=$ Jumlah pengamatan

$\mathrm{t} \quad=$ tabel $\mathrm{t}$

$\mathrm{SE} \quad=\mathrm{S}_{\mathrm{x}}^{2} / \mathrm{n}$

$\mathrm{Sx}^{2}=\frac{\sum \mathrm{x}^{2}-\left(\sum \mathrm{x}\right)^{2} / \mathrm{n}}{\mathrm{n}-1}$

Menurut Tarumingkeng (1994), penentuan pola penyebaran Ardeidae dilakukan dengan kriteria pola sebaran spasial yaitu:

a. penyebaran acak, jika $\sigma^{2}=\mu$

b. penyebaran mengelompok, jika $\sigma^{2}>\mu$

c. penyebaran sistematik atau seragam, jika $\sigma^{2}<\mu$

Nilai $\sigma^{2}$ diduga dari $S^{2}$ sementara nilai $\mu$ diduga dari nilai $\bar{X}$. 


\section{HASIL DAN PEMBAHASAN}

\section{A. Kelimpahan Spesies}

Berdasarkan hasil penelitian di Desa Kibang Pacing Kecamatan Menggala Timur Kabupaten Tulang Bawang selama 18 hari efektif pada bulan Agustus sampai dengan bulan November 2015 dijumpai 6 (enam) spesies keberadaan burung air Ardeidae yaitu blekok sawah (Ardeola speciosa) 379 perjumpaan, bambangan merah (Ixobrychus cinnamomeus) 18 perjumpaan, cangak merah (Ardea purpurea) 80 perjumpaan, kuntul besar (Egretta alba) 248 perjumpaan, kuntul kecil (Egretta garzetta) 1.165 perjumpaan dan kuntul kerbau (Bubulcus ibis) 513 perjumpaan. Jumlah keseluruhan Ardeidae sebanyak 2.403 perjumpaan.

Hasil yang diperoleh menunjukkan Ardeidae paling banyak ditemukan pada saat pengamatan di pagi hari. Rusmendro (2009) menyatakan pergerakan burung lebih banyak dilakukan pada pagi hari dibandingkan sore hari karena pada pagi hari jenis-jenis burung diurnal memulai aktivitas hariannya, terutama mencari makan. Famili ini dominan di titik pengamatan Point Count 3 (Tabel 1) yang merupakan lokasi strategis bagi burung air untuk beraktivitas dan mencari makan dengan lebih aman, karena lokasi ini jarang dilalui oleh masyarakat (manusia) dibandingkan dengan lokasi satu dan dua yang berada di dekat jalan setapak yang merupakan jalan akses masyarakat untuk masuk ke Rawa Pacing. Lokasi pada titik pengamatan Point Count 3 terdapat kanal-kanal kecil dan kubangan air yang mulai mengering. Air yang mulai mengering membuat ikan-ikan dan udang berkumpul pada kubangan air yang masih tersisa. Hal tersebut sangat disukai oleh burung air untuk mencari makan karena memudahkan dalam menangkap mangsanya. Menurut Syahadat, Erianto, dan Siahaan (2015), burung cenderung akan memilih vegetasi yang baik dan terlindung, sehingga burung merasa lebih aman untuk beraktifitas maupun tinggal. Faktor-faktor yang dapat mempengaruhi ukuran dan kepadatan populasi adalah kondisi iklim, kemampuan adaptasi suatu jenis satwa liar, interaksi antar individu maupun antar jenis, dan penyakit (Kuswanda , 2010).

Tabel 1. Spesies burung Ardeidae di Desa Kibang Pacing Kecamatan Menggala Timur.

\begin{tabular}{|c|c|c|c|c|c|c|c|c|c|}
\hline \multirow{3}{*}{ No. } & \multirow{3}{*}{ Nama Spesies } & \multicolumn{6}{|c|}{ Stasiun (Point count) } & \multirow{3}{*}{ Jumlah } & \multirow{3}{*}{ Status Dilindungi } \\
\hline & & \multicolumn{2}{|c|}{ PC 1} & \multicolumn{2}{|c|}{ PC 2} & \multicolumn{2}{|c|}{ PC 3} & & \\
\hline & & $\mathbf{P}$ & $\mathbf{S}$ & $\mathbf{P}$ & $\mathbf{S}$ & $\mathbf{P}$ & $\mathbf{S}$ & & \\
\hline 1 & Blekok sawah & 92 & 48 & 78 & 38 & 73 & 50 & 379 & (B) \\
\hline 2 & Bambangan merah & 1 & 3 & 1 & 1 & 7 & 5 & 18 & - \\
\hline 3 & Cangak merah & 12 & 6 & 16 & 13 & 18 & 15 & 80 & - \\
\hline 4 & Kuntul besar & 48 & 15 & 38 & 21 & 104 & 22 & 248 & - \\
\hline 5 & Kuntul kecil & 156 & 93 & 209 & 108 & 465 & 134 & 1.165 & (A) \\
\hline \multirow[t]{2}{*}{6} & Kuntul kerbau & 81 & 34 & 99 & 79 & 155 & 65 & 513 & (A) \\
\hline & Jumlah Total & 390 & 199 & 441 & 260 & 822 & 291 & 2.403 & \\
\hline
\end{tabular}

Keterangan:

(A): Peraturan Pemerintah No 7 Tahun 1999, (B): Undang-Undang No 5 Tahun 1990.

Perhitungan populasi Ardeidae yang dilakukan di Desa Kibang Pacing dengan metode Point Count menghasilkan kelimpahan total rerata 133 ekor pada enam spesies yang ditemukan. Rerata kelimpahan populasi Ardeidae terendah ditemukan pada spesies bambangan merah (Ixobrychus cinnamomeus) yaitu 4 ekor dan tertinggi pada spesies kuntul kecil (Egretta zargetta) yaitu 333 ekor (Tabel 2). 
Tabel 2. Populasi Ardeidae di Desa Kibang Pacing Kecamatan Menggala Timur.

\begin{tabular}{clrrr}
\hline No. & Nama Spesies & n & $\overline{\boldsymbol{X}}$ & Populasi \\
\hline 1 & Blekok sawah & 18 & 64 & 64 \\
2 & Bambangan merah & 18 & 4 & 4 \\
3 & Cangak merah & 18 & 11 & 11 \\
4 & Kuntul besar & 18 & 89 & 89 \\
5 & Kuntul kecil & 18 & 333 & 333 \\
6 & Kuntul kerbau & 18 & 112 & 112 \\
\hline Jumlah & & & 613 & 613 \\
\hline
\end{tabular}

\section{B. Pola Penyebaran}

Secara keseluruhan populasi Ardeidae di Desa Kibang Pacing memiliki pola penyebaran yang mengelompok dengan nilai varian lebih besar dari nilai rata-rata (2018 > 613) (Tabel 3). Penyebaran mengelompok terjadi apabila individu-individu selalu ada dalam kelompok dan sangat jarang terlihat sendiri secara terpisah (Michael, 1994). Pola distribusi mengelompok bisa disebabkan oleh adanya sumber makanan pada suatu habitat dalam jumlah melimpah (Nur, 2013). Hasil pengamatan menunjukkan kuntul kecil (Egretta zargetta), cangak merah (Ardea purpurea), dan bambangan merah (Ixobrychus cinnamomeus) mempunyai pola penyebaran sistematik yaitu pola penyebaran dimana individu-individu terdapat pada tempat tertentu dalam komunitas. Hal tersebut disebabkan karena terdapat persaingan yang ketat untuk mendapatkan makanan. Kuntul kecil (Egretta zargetta) merupakan spesies yang paling banyak dijumpai pada saat pengamatan. Populasinya masih cukup stabil jika dibandingkan dengan spesies lainnya sehingga timbul kompetisi yang mendorong pembagian ruang hidup yang sama. Selain itu tempat berburu makan di Rawa Pacing yang mulai kekeringan dan ikan-ikan sebagai sumber pakan alami yang tersedia terus berkurang akibat dari musim kemarau membuat persaingan untuk berburu menjadi lebih ketat. Pola penyebaran mengelompok terjadi pada spesies blekok sawah (Ardeola speciosa), kuntul besar (Egretta alba), dan Kuntul kerbau (Bubulcus ibis) dimana individu-individu selalu ada dalam kelompok-kelompok dan sangat jarang terlihat sendiri secara terpisah. Pola ini umumnya dijumpai di alam, karena adanya kebutuhan akan faktor lingkungan yang sama.

Tabel 3. Pola Penyebaran Ardeidae yang terdapat di Desa Kibang Pacing Kecamatan Menggala Timur Kabupaten Tulang Bawang.

\begin{tabular}{clrrl}
\hline No. & Nama Spesies & \multicolumn{1}{c}{$\mathbf{S}^{\mathbf{2}}$} & $\overline{\boldsymbol{X}}$ & Pola Penyebaran \\
\hline 1 & Blekok sawah & 399 & 64 & Mengelompok \\
2 & Bambangan merah & 1 & 4 & Sistematik \\
3 & Cangak merah & 10 & 11 & Sistematik \\
4 & Kuntul besar & 504 & 89 & Mengelompok \\
5 & Kuntul kecil & 7 & 333 & Sistematik \\
6 & Kuntul kerbau & 1.096 & 112 & Mengelompok \\
\hline Jumlah & & 2.018 & 613 & Mengelompok \\
\hline
\end{tabular}

\section{Vegetasi dan Fungsi Habitat Bagi Burung}

Kondisi umum areal pengamatan diamati dengan metode rapid assessment merupakan modifikasi dari habitat assessment untuk mendapatkan gambaran secara umum tipe vegetasi 
ditemukannya keberadaan burung. Desa Kibang Pacing merupakan daerah rawa yang sebagian wilayahnya telah dimanfaatkan masyarakat sebagai daerah perkebunan dan pertanian. Genangan air dan lumpur sepanjang tahun menjadi tempat hidup serta berkembang biak berbagai macam jenis ikan yang merupakan makanan utama burung Ardeidae. Selain berlimpahnya makanan di Rawa Pacing juga terdapat vegetasi semak yang rapat dan masih banyaknya pohon gelam yang menjadi pendukung bagi burung Ardeidae untuk mencari makan, membuat sarang, membuat tempat berlindung, dan beristirahat.

Pohon yang dijadikan sebagai berlindung dan beristirahat adalah pohon gelam (Melaleuca leucadendra L.). Pohon gelam (Melaleuca leucadendra L.) tumbuh tinggi, mempunyai tajuk yang rapat dan batang yang kuat serta tumbuh secara berkelompok membuat burung Ardeidae memanfaatkan pohon tersebut sebagai tempat untuk berlindung dari gangguan predator dan beristirahat. Hal tersebut dapat dibuktikan dengan banyak ditemukannya kotoran-kotoran burung Ardeidae di bawah pohon gelam (Melaleuca leucadendra L.).

\section{Gangguan dan Ancaman Terhadap Burung}

Lokasi pengamatan merupakan daerah rawa yang ditanami sawit (kecil) dengan dikelilingi kanal-kanal di sisi maupun di tengah kebun. Kebun sawit tersebut di tumbuhi rumput yang dimanfaatkan masyarakat di Desa Kibang Pacing dan sekitarnya untuk pakan ternak yaitu kambing, sapi, dan kerbau. Selain itu masyarakat di Rawa Pacing dan sekitarnya juga sering melakukan kegiatan menangkap ikan di kanal yang menjadi lokasi pengamatan dengan cara yang masih tradisional yaitu dengan cara memancingnya, dan dengan menggunakan jala atau jaring untuk menangkap ikan.

Sumber pakan alami yang tersedia hampir sepanjang tahun, ikan merupakan daya tarik bagi burung-burung migran untuk datang setiap tahunnya. Apabila ketersediaan pakan alami telah berkurang atau bahkan habis tentu akan sangat mengancam keberadaan burung air di daerah ini. Selain itu perburuan burung Ardeidae di Rawa Pacing masih dilakukan oleh beberapa warga Kibang Pacing dan sekitarnya untuk dikonsumsi sendiri. Selama pengamatan hanya ditemukan satu orang warga saja yang menyatakan telah melakukan perburuan terhadap burung air di Rawa Pacing. Dengan adanya aktivitas tersebut tentu sangat mengganggu dalam pengambilan data serta merupakan ancaman bagi burung-burung air di Rawa Pacing.

\section{KESIMPULAN}

Berdasarkan penelitian di Desa Kibang Pacing Kecamatan Menggala Timur Kabupaten Tulang Bawang dapat disimpulkan bahwa:

1. Terdapat 6 (enam) spesies burung air Ardeidae yaitu blekok sawah (Ardeola speciosa) 379 perjumpaan, bambangan merah (Ixobrychus cinnamomeus) 18 perjumpaan, cangak merah (Ardea purpurea) 80 perjumpaan, kuntul besar (Egretta alba) 248 perjumpaan, kuntul kecil (Egretta garzetta) 1.165 perjumpaan, kuntul kerbau (Bubulcus ibis) 513 perjumpaan dan jumlah keseluruhan Ardeidae sebanyak 2.403 perjumpaan.

2. Kelimpahan jenis blekok sawah (Ardeola speciosa) sebanyak 64 ekor, bambangan merah (Ixobrychus cinnamomeus) 4 ekor, Cangak merah (Ardea purpurea) 11 ekor, kuntul besar (Egretta alba) 89 ekor, kuntul kecil (Egretta garzetta) 333 ekor, dan kuntul kerbau (Bubulcus ibis) 112 ekor.

3. Pola penyebaran keseluruhan famili Ardeidae adalah mengelompok dengan nilai varian lebih besar dari nilai rata-rata $(2.018>613)$. 


\section{DAFTAR PUSTAKA}

Badan Pusat Statistik. 2014. Statistik Daerah Kabupaten Tulang Bawang 2014. Badan Pusat Statistik Tulang Bawang. Tulang Bawang. 12 p.

Chrystanto. 2014. Keanekaragaman jenis avifauna di Cagar Alam Keling II/III Kabupaten Jepara Jawa Tengah. Indonesian Journal of Conservation. 3(1):1-6.

Howes, J. D., Bakewell., Y. R. Noor. 2003. Panduan Studi Burung Pantai. Buku. Wetlands International - Indonesia Programme. Bogor. $331 \mathrm{p}$.

Kuswanda, W. 2010. Pengaruh komposisi tumbuhan terhadap populasi burung di Taman Nasional Batang Gadis, Sumatera Utara. Jurnal Balai Penelitian Kehutanan Aek Nauli. 7(2):193-213.

Kwatrina, R. T., Kuswanda, W., dan Setyawati, T. 2013. Sebaran dan kepadatan populasi siamang (Symphalangus syndactylus Raffles, 1821) di Cagar Alam Dolok Sipirok dan sekitarnya, Sumatera Utara. Jurnal Penelitian Hutan dan Konservasi Alam. 10(1):81-91.

MacKinnon J., K. Philips, B. Van Balen. 2010. Burung-burung di Sumatera, Jawa, Bali, dan Kalimantan. Buku. Puslitbang Biologi-LIPI. Bogor. 509 p.

Michael, P. E. 1994. Metode Ekologi untuk Penyelidikan Ladang dan Laboratorium. Buku. Universitas Indonesia. Jakarta. 616 p.

Nur, R. F., W. Novarianto, dan J. Nurdin, 2013. Kelimpahan dan pola distribusi burung rangkong (Bucerotidae) di kawasan P.T Kencana Sawit Indonesia (KSI) Solok Selatan, Sumatera Barat. Jurnal Semirata. 2(1):27-33.

Noerdjito, M., Dan I. Maryanto. 2001. Jenis-Jenis Hayati yang Dilindungi Perundangundangan Indonesia. Buku. Balitbang Zoologi, Puslitbang Biologi-LIPI dan The Nature Conservancy. Bogor. 217 p.

Rusmendro, H. 2009. Perbandingan keanekaragaman burung pada pagi dan sore hari di empat tipe habitat di wilayah Pangandaran Jawa Barat. Jurnal Vis Vitalis. 2(1):816.

Syahadat. F., Erianto, dan S., Siahaan. 2015. Studi keanekaragaman jenis burung diurnal di hutan mangrove Pantai Air Mata Permai Kabupaten Ketapang. Jurnal Hutan Lestari. 3(1):21-29.

Tarumingkeng, R. C. 1994. Dinamika Populasi Kajian Ekologi Kuantitatif. Buku. Pustaka Sinar Harapan dan Universitas Kristen Krida Wacana. Jakarta. 284 p.

Yuniar, A. 2007. Studi Populasi dan Habitat Merak Hijau (Pavo muticus Linnaeus, 1766) di Taman Nasional Baluran Jawa Timur. Buku. Departemen Konservasi Sumberdaya Hutan dan Ekowisata Institut Pertanian Bogor. Bogor. 125 p. 
Vol. 4 No. 2, April 2016 (109-116)

Halaman ini sengaja dikosongkan 